\title{
Study and Enhanced Design of RF Dual Band Bandpass Filter Validation and Confirmation of Experimental Measurements
}

\author{
Mohamed Mabrouk, Leila Bousbia \\ CIRTACOM and ISETCOM of Tunis, University of Carthage, Tunis, Tunisia \\ E-mail: mohamed.mabrouk@isetcom.rnu.tn \\ Received July 22, 2011; revised August 12, 2011; accepted August 21, 2011
}

\begin{abstract}
Dual band bandpass filter is designed and optimized for RF wireless applications. The performances of that RF dual band filter are improved especially parameters describing the insertion loss, return losses and rejection. Dual band bandpass filter using stub loaded resonators is designed and characterized. Theoretical results are compared with experimental data. This comparison shows that the magnitude of reflection coefficient $\mathrm{S}_{11}$ from $\mathrm{ADS}^{\mathrm{TM}}$ simulation is better than $28.0 \mathrm{~dB}$, and the insertion loss $\mathrm{S}_{21}$ is less than $0.5 \mathrm{~dB}$. The two rejections are also better than $32.0 \mathrm{~dB}$. The simulated results also show that two central frequencies are located at desired 1.82 and $2.95 \mathrm{GHz}$. Comparison of measured and simulated results shows frequency drift. The main reason for this frequency shifting is due to some uncertainties. These are obviously due to geometrical and physical parameters $\mathrm{H}$ and $\varepsilon r$ respectively of Duroid substrate used during design and measurements.
\end{abstract}

Keywords: RF Filters, Dual Bandpass, Effective Permittivity, Physical and Geometrical Parameters

\section{Introduction}

RF circuits with a dual pass band operation are required by modern wireless communication systems [1]. For example, the RF transceiver length (TX/RX) for second generation GSM and third-generation WCDMA mobile communications must be able to receive and transmit $900 \mathrm{MHz}$ and $1900 \mathrm{MHz}$ signals. Also $2.4 \mathrm{GHz}$ and 5.2 $\mathrm{GHz}$ bands are two bands operated by high-speed wireless LANs $[1,2]$. The band pass filter is necessary to generate two or more transmission frequency bands, in particular dual-band filters, as they have an essential role in transmit-receive systems [2]. RF filters have particularly an important role for signals filtering, rejection and isolation between parts in transceivers systems (TX/RX). Filters have the characteristic to be frequency selective devices for transmitting and attenuating signal in desired frequency ranges [3]

Many different ways are considered to design dualband bandpass filters such combination of two filters operating on two different bandwidths [4] and using dual band stepped impedances resonator [5] or dual band stubs resonators [6]. Quasi lumped with open loop band pass filters operating at different frequency bands [7] and using square loop dual mode resonators [8] are also used for designing this type of filters. Small insertion loss, low return loss and high rejection band are the desired characteristics of a good filter. The design of this kind of filter is considered using electromagnetic (EM) simulators. The studied filter was simulated using $\mathrm{IE}^{\mathrm{T}}{ }^{\mathrm{TM}}$ [6], and in this paper we report our ADS $^{\mathrm{TM}}$ simulation optimized results which are very close to the experimental measurements. $\mathrm{ADS}^{\mathrm{TM}}$ software has been used successfully many times for simulation design filter so that the resulting performances meet the microwave filter specifications. Simulated results confirm that two central frequencies are located at desired values $1.82 \mathrm{GHz}$ and $2.95 \mathrm{GHz}$.

\section{Design Description of Band Pass Filter}

The studied filter is composed of two ring-resonators loaded with two open stubs. Figure 1 shows the physical layout of the dual band pass filter using uniform microstrip lines. This filter consists of two microstrip open loops. Two open circuited stubs are attached [6] at 
the center of the respective microstrip lines. The total length of each resonator is around half wave length $\left(\lambda_{\mathrm{g}} / 2\right)$.

The design parameters dimensions are chosen [6] as following: $\mathrm{W}=1.2 \mathrm{~mm} ; \mathrm{W}_{1}=1.5 \mathrm{~mm} ; \mathrm{W}_{2}=0.9 \mathrm{~mm}$; $\mathrm{L}=11.2 \mathrm{~mm} ; \mathrm{L}_{1}=6.7 \mathrm{~mm} ; \mathrm{g}_{1}=\mathrm{g}_{2}=0.3 \mathrm{~mm}$. The structure of open-loop resonators filter with center frequency of $1.82 \mathrm{GHz}$ and $2.94 \mathrm{GHz}$ is designed on an RT Duroid 6006 substrate with a thickness $\mathrm{H}=0.635 \mathrm{~mm} \pm 0.0254$ and a relative dielectric constant $\varepsilon_{\mathrm{r}}=6.15 \pm 0.15$ [9].

\section{Analysis and Comparison of Simulation with Measurement Results}

Figures 2 and 3 illustrate simulated and measured $S_{21}$ and $S_{11}$ parameters respectively of our studied dual band filter.

Simulated results show that two central frequencies are located at the desired values $1.82 \mathrm{GHz}$ and $2.95 \mathrm{GHz}$, and a small frequency shifting is observed. Thus, the $\mathrm{ADS}^{\mathrm{TM}}$ simulation results are shifted of $-5.0 \mathrm{MHz}$, (1.825 GHz instead $1.830 \mathrm{GHz}$ ), and of $+13.0 \mathrm{MHz}$ (2.953 GHz instead $2.940 \mathrm{GHz}$ ). To understand the main reason for this frequency shifted aberration which is certainly due to the uncertainties on the guided wave length $\lambda_{\mathrm{g}}$, we have highlighted the following relationships:

$$
\lambda_{\mathrm{g}}=\frac{\mathrm{C}}{\mathrm{F} \sqrt{\varepsilon_{\mathrm{eff}}}}
$$

where $\mathrm{F}$ is the center frequency of the filter and $\mathrm{c}$ is the light velocity. The effective dielectric constant is depending on relative permittivity $\varepsilon_{\mathrm{r}}$ and ratio $\mathrm{W} / \mathrm{H}$ between the width $\mathrm{W}$ of the transmission line and the thickness $\mathrm{H}$ of the substrate which is given in the following forms. The RT Duroid 6006 laminate substrate is available with relative permittivity $\varepsilon_{\mathrm{r}}$ value $\varepsilon_{\mathrm{r}}=6.15$ \pm 0.15 .

It's known that the Equation (2) shows below the effective permittivity $\varepsilon_{\text {eff }}$ of the microstrip structure, used

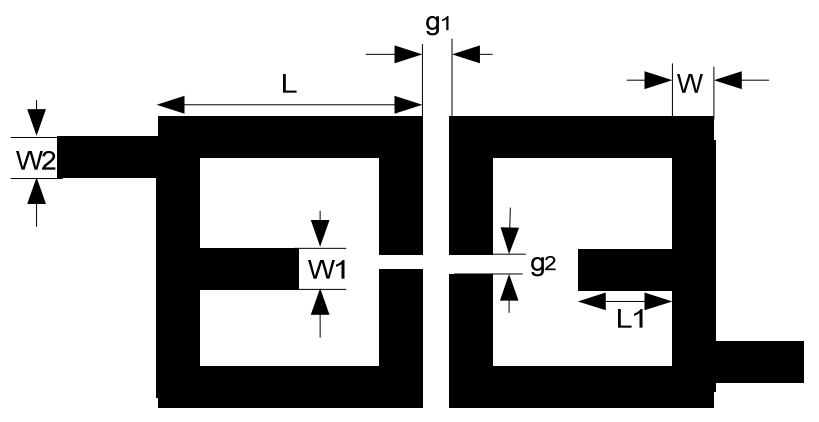

Figure 1. Layout of dual band filter.

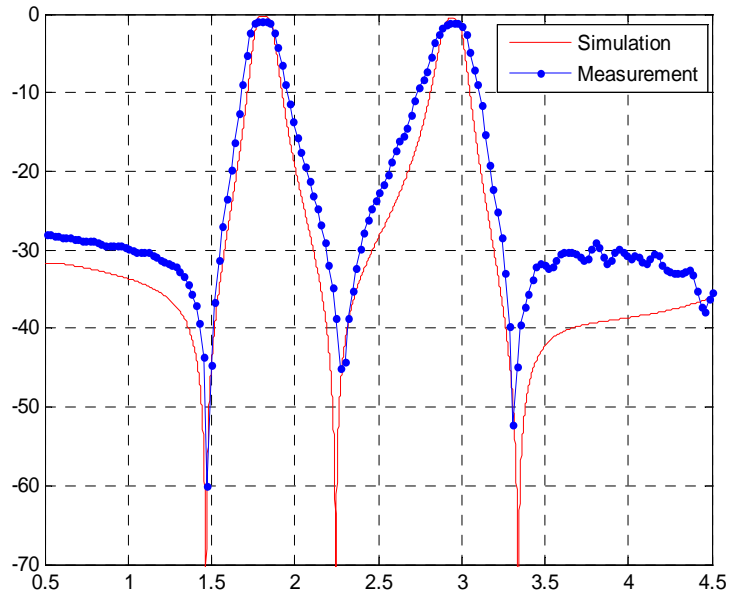

Figure 2. Simulated and measured $S_{21}$ parameters of dual band filter.

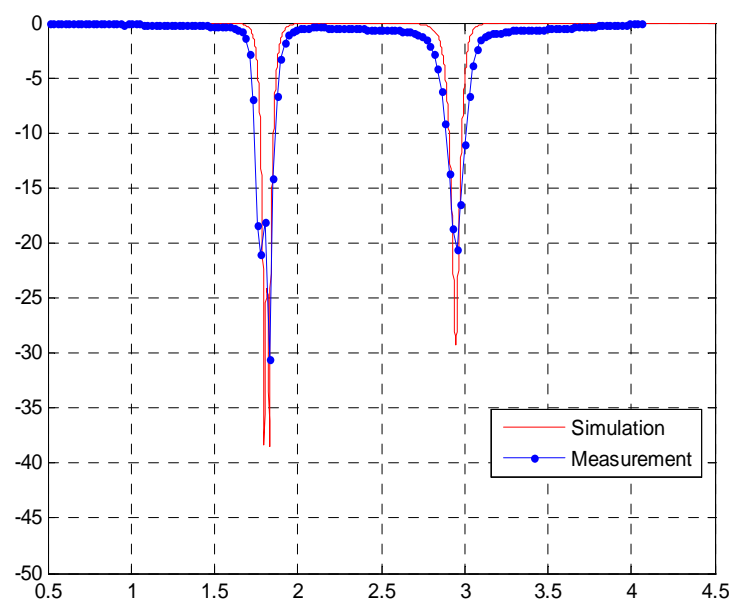

Figure 3. Simulated and measured $S_{11}$ parameters of dual band filter.

in our design, depends on the relative dielectric constant $\varepsilon_{\mathrm{r}}$, which is one of physical parameters of Duroid substrate, and the guided wave length $\lambda_{\mathrm{g}}$ also depends on $\varepsilon_{\text {eff }}$, so the resonant frequencies of our filter are closely depending on $\lambda_{\mathrm{g}}$ according to the Equation (1).

For $\mathrm{W} / \mathrm{H} \geq 1$, the empirical relationship of the effective permittivity is summarized below [10-12]:

$$
\varepsilon_{\text {eff }}=\frac{\varepsilon_{\mathrm{r}}+1}{2}+\frac{\varepsilon_{\mathrm{r}}-1}{2}\left[1+12 \frac{\mathrm{H}}{\mathrm{W}}\right]^{-\frac{1}{2}}
$$

Because of the uncertainty on the dielectric relative permittivity $\varepsilon_{\mathrm{r}}$ of Duroid substrate recalled previously (in §2), we can evaluate $\varepsilon_{\text {eff }}$ as following:

$$
4.476 \leq \varepsilon_{\text {eff }} \leq 4.553
$$




$$
76 \mathrm{~mm} \leq \lambda_{\mathrm{g}} \leq 78 \mathrm{~mm}
$$

Thus, we can deduce that the first resonant frequency $\mathrm{F}_{\mathrm{C} 1}$ is the following:

$$
1.79 \mathrm{GHz} \leq \mathrm{F}_{\mathrm{C} 1} \leq 1.84 \mathrm{GHz}
$$

For the second frequency $\mathrm{F}_{\mathrm{C} 2}$, we can also do the same line of argument as following:

$$
47 \mathrm{~mm} \leq \lambda_{\mathrm{g}} \leq 48 \mathrm{~mm}
$$

That means $\mathrm{F}_{\mathrm{C} 2}$ is:

$$
2.94 \mathrm{GHz} \leq \mathrm{F}_{\mathrm{C} 2} \leq 3.06 \mathrm{GHz}
$$

These equations confirm the first explicit reason for this frequency shifting is due to the uncertainty on the first physical parameter, i.e. the dielectric relative permittivity $\varepsilon_{\mathrm{r}}$ of Duroid substrate.

In the same line of argument, we can see that the uncertainty on the substrate thickness $\mathrm{H}$ can lead the following limits for the first frequency $\mathrm{F}_{\mathrm{C} 1}$ :

$$
\begin{gathered}
4.47 \leq \varepsilon_{\text {eff }} \leq 4.507 \\
77 \mathrm{~mm} \leq \lambda_{\mathrm{g}} \leq 78 \mathrm{~mm} \\
1.810 \mathrm{GHz} \leq \mathrm{F}_{\mathrm{C} 1} \leq 1.850 \mathrm{GHz}
\end{gathered}
$$

For the second frequency $\mathrm{F}_{\mathrm{C} 2}$ :

$$
\begin{gathered}
4.47 \leq \varepsilon_{\text {eff }} \leq 4.507 \\
47 \mathrm{~mm} \leq \lambda_{\mathrm{g}} \leq 48 \mathrm{~mm} \\
2.910 \mathrm{GHz} \leq \mathrm{F}_{\mathrm{C} 2} \leq 3.0 \mathrm{GHz}
\end{gathered}
$$

Here again, it's confirmed that the uncertainty on thickness $\mathrm{H}$ can obviously contribute to the frequency shifting that we observed, and the differences between center frequencies are surely due to the cumulative effects of both uncertainties on $\varepsilon_{\mathrm{r}}$ and $\mathrm{H}$. We have made a comparative study of our simulation results and experimental measurements obtained and provided by our partner Zhang. Nevertheless, these differences that we observed on the frequency values, between our simulations and the measurements of our partner Zhang, are remaining very small. Thus, the difference of $5.0 \mathrm{MHz}$ on the first resonance frequency $(1.830$ $\mathrm{GHz}$ ) between our simulation results and the measurements of Zhang is about $0.27 \%$, while the difference of $150.0 \mathrm{MHz}$ observed $(1.680 \mathrm{GHz}$ instead $1.830 \mathrm{GHz}$ ) between the first simulation results of Zhang and the experimental measurements is about $8.0 \%$. The difference of $13.0 \mathrm{MHz}$ on the second resonance frequency $(2.94 \mathrm{GHz})$ between our simulation results and the measurements of Zhang is about $0.44 \%$, and the difference of $130.0 \mathrm{MHz}$ observed by Zhang (2.81 GHz instead $2.94 \mathrm{GHz}$ ) is about $4.4 \%$. The little disagreement we have obtained with the experimental measurements confirms our predictions, and our indepth analysis shows that we can notably improve some characteristics of the studied filter with going in detail and making further development, consequently of the global performances become enhanced.

Regarding the insertion and return losses, Figure 4 shows simulated and measured insertion loss $S_{21}$ and return loss $S_{11}$ parameters respectively of our dual band filter. We obtained $S_{21}$ significantly lower than $0.28 \mathrm{~dB}$ instead of $0.9 \mathrm{~dB}$ measured at $\mathrm{F}_{\mathrm{C} 1}$, and $0.4 \mathrm{~dB}$ instead of $1.1 \mathrm{~dB}$ measured at $\mathrm{F}_{\mathrm{C} 2}$ respectively. Our simulated $\mathrm{S}_{21}$ results depicted on Figure 2 are up to $10.0 \mathrm{~dB}$ better at $4.0 \mathrm{GHz}$ than the measurements. Figure 3 also shows that our simulated results of return loss $S_{11}$ are up to $8.0 \mathrm{~dB}$ better at $4.0 \mathrm{GHz}$ than the measurements, and the obtained return loss $\mathrm{S}_{11}$ is better than $28.0 \mathrm{~dB}$.

Moreover, the simulated filter using two open loop ring resonators shows better rejections than the measured ones, $31.0 \mathrm{~dB}$ instead of $28.0 \mathrm{~dB}$ measured at 0.5 $\mathrm{GHz}$ and $37.0 \mathrm{~dB}$ instead of $31.0 \mathrm{~dB}$ measured at 4.5 GHz. Table 1 shows comparative results.

\section{Conclusions}

We have studied and enhanced the design of dual band bandpass filter for RF and wireless applications. The performances of RF dual-band filter are improved especially parameters describing the insertion loss, return losses and rejections. We have obtained a good agreement between our simulations and experimental results. Insertion loss $\mathrm{S}_{21}$ lower than $0.5 \mathrm{~dB}$ and return loss $\mathrm{S}_{11}$ better than $28.0 \mathrm{~dB}$ were obtained from ADS simulations. The rejections are also better than $32.0 \mathrm{~dB}$. Simulated results show that two central frequencies are located at desired 1.820 and $2.950 \mathrm{GHz}$. Comparison of measured and simulated results shows frequency shift. This is obviously due to the uncertainties on the geometrical and

Table 1. Comparison of Zhang measurements [5] and our simulations.

\begin{tabular}{ccc}
\hline & $\begin{array}{c}\text { Measurement } \\
\text { Results } \\
\text { of Zhang [5] }\end{array}$ & Our results \\
\hline Resonance Frequency $\mathrm{F}_{\mathrm{C} 1}$ & $1.830 \mathrm{GHz}$ & $1.825 \mathrm{GHz}$ \\
Resonance frequency $\mathrm{F}_{\mathrm{C} 2}$ & $2.940 \mathrm{GHz}$ & $2.953 \mathrm{GHz}$ \\
Band Pass 1 & $9.4 \%$ & $6.7 \%$ \\
Band Pass 2 & $7.5 \%$ & $4.37 \%$ \\
Insertion losses at $\mathrm{F}_{\mathrm{C} 1}$ & $0.9 \mathrm{~dB}$ & $0.28 \mathrm{~dB}$ \\
Insertion losses2 at $\mathrm{F}_{\mathrm{C} 2}$ & $1.1 \mathrm{~dB}$ & $0.4 \mathrm{~dB}$ \\
Return loss at $\mathrm{F}_{\mathrm{C} 1}$ & $24.0 \mathrm{~dB}$ & $29.25 \mathrm{~dB}$ \\
Return loss at $\mathrm{F}_{\mathrm{C} 2}$ & $20.0 \mathrm{~dB}$ & $28.81 \mathrm{~dB}$ \\
Rejection at $0.5 \mathrm{GHz}$ & $28.0 \mathrm{~dB}$ & $31.64 \mathrm{~dB}$ \\
Rejection at $4.0 \mathrm{GHz}$ & $31.0 \mathrm{~dB}$ & $38.64 \mathrm{~dB}$ \\
\hline
\end{tabular}




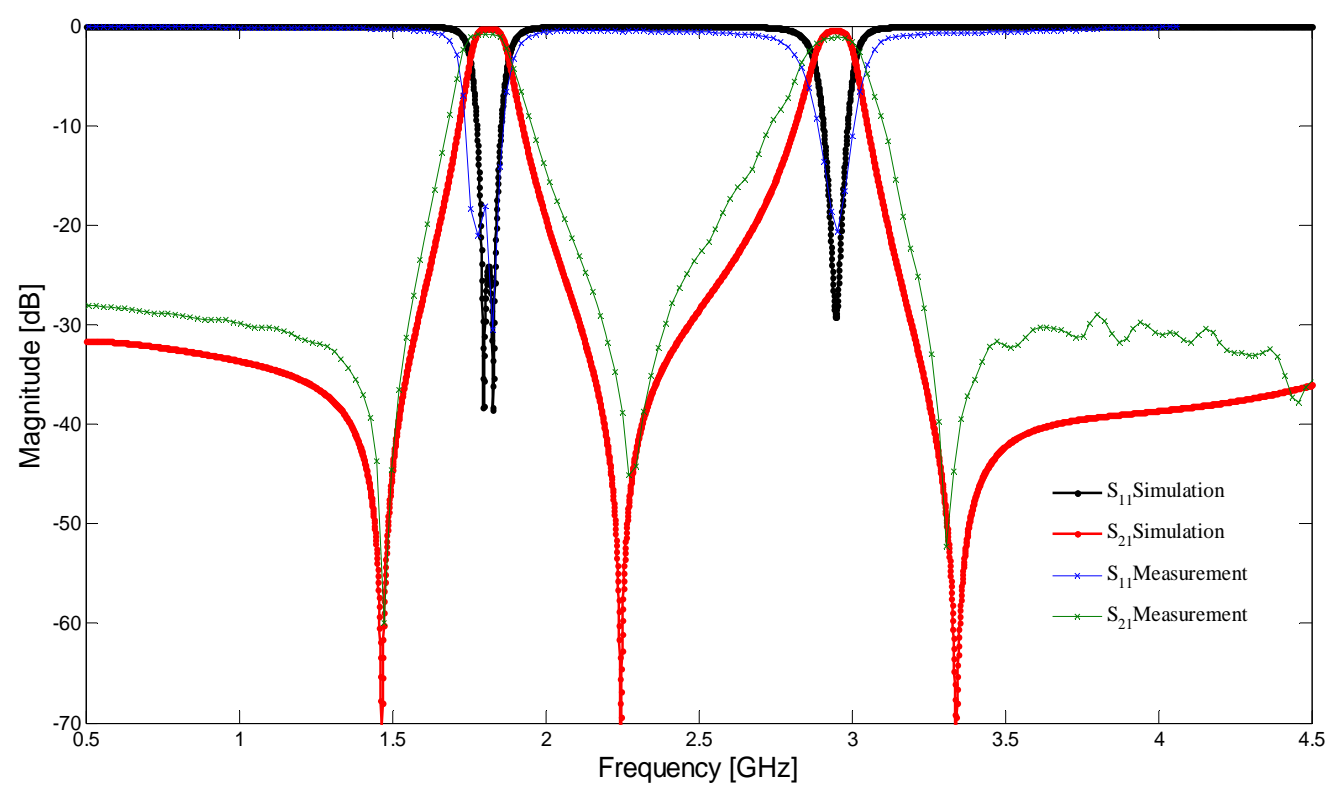

Figure 4. Simulated and measured $S_{11}, S_{21}$ parameters of dual-band filter.

physical parameters $H$ and $\varepsilon_{\mathrm{r}}$ respectively of Duroid substrate used during design and measurements.

\section{Acknowledgements}

The authors would like to acknowledge and extend their gratitude to our partner Xiu Yin Zhang, Associate Professor with the School of Electronic and Information Engineering (South China University of Technology, Guangzhou, 510641, China) who has carried out and provided the experimental measurements of studied prototype of filter.

\section{References}

[1] C. Y. Chen, C. Y. Hsu and H. R. Chuong, "Design of Miniature Planar Dual Band Filter Using Dual-Feeding Structures and Embedded Resonators," IEEE Microwave and Wireless Components Letters, Vol. 16, No. 12, 2006, pp. 669-671. doi:10.1109/LMWC.2006.885621

[2] S. F. Chang, Y. H. Jeng and J. L. Chen, "Dual-Band Step Impedance Band Pass Filter for Multimode Wireless LANs,” Electronic Letters, Vol. 40, No. 1, 2004, pp. 38-39. doi:10.1049/el:20040065

[3] I. C. Hunter, L. Billonet, B. Jarry and P. Guillon, "Microwave Filters-Applications and Technology," IEEE Microwave Theory and Techniques Transactions, Vol. 50, No. 3, March 2002, pp. 794-805. doi:10.1109/22.989963

[4] H. Miyake, S. Kitazawa, T. Ishizaki, T. Ymanda and Y. Nagatomi, “A Miniaturized Monolithic Dual-band Filter Using Ceramic Lamination Technique for Dual Mode Portable Telephones," IEEE MTT-S International Micro- wave Symposium Digest, 8-13 June 1997, Vol. 2, pp. 789-792.

[5] J. T. Kuo, T. H. Yeh and C. Yeh, "Design of Microstrip Bandpass Filters with a Dual Pass Band Response,” IEEE Microwave Theory and Techniques Transactions, Vol. 53, No. 4, April 2005, pp. 1331-1337. doi:10.1109/TMTT.2005.845765

[6] X. Y. Zhang, J. X. Chen and Q. Xue, "Dual-band Band Pass Filters Using Stub-Loaded Resonators,” IEEE Microwave and Wireless Components Letters, Vol. 17, No. 8, 2007, pp. 583-585. doi:10.1109/LMWC.2007.901768

[7] A. Balalem, W. Menzel and A. Omar, "Quasi Lumped Open Loop Suspended Stripline Bandpass Filters,” 36 ${ }^{\text {th }}$ European Microwave Conference, Manchester, 10-15 September 2006, pp. 568-571.

[8] A. Balalem, J. Machac and A. Omar, "Dual-band Bandpass Filter by Using Square Loop Dual Mode Resonator," International Journal of Microwave and Optical Technology, Vol. 50, No. 6, June 2008, pp. 1567-1570. doi:10.1002/mop.23427

[9] “RT/duroid® 6006/6010LM High Frequency Laminates,” 1998.

http://www.rogerscorp.com/documents/612/acm/RT-duro id-6006-6010-laminate-data-sheet

[10] M. V. Schneider, "Microstrip Lines for Microwave Integrated Circuits,” The Bell System Technical Journal, Vol. 48, No. 5, 1969, pp. 1421-1444.

[11] H. A. Wheeler, "Transmission Line Properties of a Strip on a Dielectric Sheet on a Plane," IEEE Microwave Theory and Techniques Transactions, Vol. 25, No. 8, 1977, pp. 631-647. doi:10.1109/TMTT.1977.1129179

[12] K. C. Gupta, et al., "Computer-Aided Design of Microwave Circuits,” Artech House, Dedham, 1981, pp. 131-134. 